\title{
Detection of Pentastomida on Crab-Eating Frog (Fejervarya cancrivora) in Surabaya and Sidoarjo Areas
}

\author{
${ }^{1)}$ Gilang Maulana Putra, ${ }^{2}$ Emmanuel Djoko Poetranto, ${ }^{3)}$ Fedik Abdul Rantam \\ ${ }^{1)}$ Student, Faculty of Veterinary Medicine, Universitas Airlangga \\ ${ }^{2)}$ Department of Veterinary Clinic, Faculty of Veterinary Medicine, Universitas Airlangga, \\ ${ }^{3)}$ Department of Veterinary Microbiology, Faculty of Veterinary Medicine, Universitas Airlangga,
} Corresponding author: e-djoko-p@fkh.unair.ac.id

\begin{abstract}
This research was conducted to detect the presence of Pentastomida on Crab-eating Frog (Fejervarya cancrivora) in Surabaya and Sidoarjo areas. A total of 50 samples were taken in three different time and the identification was conducted in Laboratory of Parasitology, Universitas Airlangga by Semichen-Acetic Carmine staining method. Pentastomida that found in the body of Crab-eating Frog (Fejervarya cancrivora) was belong to Maxillopoda class which is included in Crustacea subphylum were matched by macroscopic and microscopic taxonomy and observation. The result of this research showed that there found Pentastomida on Crab-eating Frog collected Surabaya and Sidoarjo areas, East Java.
\end{abstract}

Keywords: frogs, crustacea, pentastomida, semichen-acetic, Carmine, Fejervarya cancrivora.

\section{Introduction}

Indonesia's geographical location exactly on the equator line and it is strategic because Indonesia located between two continents, Asia and Australia and between two oceans. This conditions made Indonesia the world's most unique area which has the richest biodiversity around the world (Sukara and Tobing, 2008)

Indonesia has a lot of diversity in various kind of animal species or wildlife, one of them is the kinds of amphibian, the diversity of amphibian species place Indonesia in sixth ranks, respectively, at global level. Hosting 392 amphibian species and the largest amphibian population in Asia. Indonesia also has the second highest endemic species in Asia, with 175 amphibian species being endemic to it rainforest habitats (Kusrini, 2006).

Frogs are right in the middle of the food chain and serve as indicators of environmental health. They play an important role as pest control (consuming insects that may be agricultural pest or carry diseases such as West Nile Virus) and one of food source for birds, snakes and other animals throughout the food web, including humans.

Indonesia is one of the world's largest exporters of frogs' legs for consumption as food. The majority of the frogs are caught in natural habitat on the island of Java predominantly the Crab-eating Frog (Fejervarya cancrivora) (75\%), and the Giant Javan Frog (Limnonectes macrodon) (19\%). Europe was the major importer of Indonesian frogs' legs (83.2\% of the total exported), with Belgium and Luxembourg the principal destination (47.6\%), followed by France (27.6\%) and Netherlands (21\%) (Kusrini and Alford, 2006).

In the eastern part of Java island only crabeating frog ( $F$. cancrivora), grass frog ( $F$. limnocharis), and sometimes fanged river frog (L. macrodon) were consumed or sold. Most of the frogs that were sold in the market was caught in their natural habitat and only few of them were actually came from a frog's breeder or farm (Kusrini and Alford, 2006). According to Kusrini (2006) Indonesia were known as one of the country with a large diversity of amphibian life within the country but unfortunately there is only a few study for amphibian life in Indonesia especially to a frog.

Most emerging infectious diseases are zoonotic; wildlife constitutes a large and often unknown reservoir. Wildlife can also be a source for reemergence of previously controlled zoonoses. Although the discovery of such zoonoses is often related to better diagnostic tools, the leading causes of their emergence are human behavior and modifications to natural habitats (expansion of human populations and their encroachment on wildlife habitat), changes in agricultural practices, and globalization of trade. However, other factors include wildlife trade and translocation, live animal and bush meat markets, consumption of exotic foods, development of ecotourism, access 
to petting zoos, and ownership of exotic pets. To reduce risk for emerging zoonoses, the public should be educated about the risks associated with wildlife, bush meat, and exotic pet trades; and proper surveillance systems should be implemented (Chomel et al., 2007).

Wildlife animal is one of many sources of parasite including zoonotic parasite. Worm is the most common parasite found in human consumed frog. The most common worm parasite infects frog are Pentastomida, Spirometra sp., Acanthocephala, Contracaecum and roundworms. Pentastomida is worm-like parasite that have predilection in respiratory tract of vertebrates. Frog is the intermediate host of this parasite.The larva hatches in intermediate host and breaks through the wall of the intestine (Barnes, 1982). Not only animals, pentastomida also can infects human (Paré, 2008; Sundar et al., 2015).

Some of worm parasite and Pentastomida that can be found in frog are zoonotic, for example larva of Gnathosoma sp. (Cha et al., 2003; Cho et al., 2007) and larva of Spirometra sp. larvae (Annable and Metcalfe, 2012). Visceral pentastomiasis caused by Armillifer moniliformis in a 70-year-old Aboriginal farmer from rural Malaysian Borneo by Tappe et al. (2011) in Malaysia.

\section{Materials and Methods}

This research was conducted at the Laboratory of Parasitology, Department of Parasitology, Faculty of Veterinary Medicine, Universitas Airlangga, Surabaya. This research was started on March 2018. Frog samples was taken from fish pond, trench and rice fields area of Surabaya and Sidoarjo.

The main material of this research was the collected Pentastomida from the body of the frog. First of all, the extant frog euthanized by damaging the brain of the mentioned frog. This technique done by puncturing a needle at the curvature between the frog's cranium and columna vertebralis, the needle then to be moved until both of the frog's limbs became limp and both are showing extension position. Then the frog was placed within a board and fixated by piercing all of it's limbs to the board with a needle. The frog necropsy started by making a $\mathrm{Y}$ shaped cut at the thoracic and abdominal cavity of the frog, this process must be done carefully and done by using a surgical scissor. The skin was cut using a surgical forceps with left hand whilst the right hand starting to cut the skin using a surgical scissor, this process must be done very carefully to prevent damaging another organ. After the abdominal skin were opened, start cutting the frog's skin from the abdominal area to the dorsal area and the extremity area of the frog. Observe if there were any Pentastomida that can be found at the frog's body (Wright and Whitaker, 2001).

The discovered Pentastomida were fixated between two object glasses using a loosely bounded string on each end of the object glass. The Pentastome then soaked with $5 \%$ alcohol glycerin solution for 24 hours before soaked with $70 \%$ alcohol for 5 minutes. The object glass contained with the Pentastome then dipped into a diluted carmine solution and left to dry for approximately 8 hours depends on how thick the Pentastomid's cuticle is. The Pentastome then was removed from the object glass and soaked with acid alcohol for 2 minutes and then soaked with alkali alcohol for 20 minutes. Then gradual dehydration process was conducted by dipping the Pentastome to an alcohol solution with various concentration from $70 \%$ to $95 \%$ for 5 minutes each. After the gradual dehydration process completed, mounting was conducted using Hung's I solution for 20 minutes before the Pentastomida were taken and placed to a new object glass. A few drop of Hung's II solution have been given to the Pentastome sample before covering it with an object glass. The last step of this staining process is drying using an incubator with the temperature set at $37^{\circ} \mathrm{C}$ before left to cold in a room temperature. This Semichen-Acetic Carmine staining process referring to Kuhlmann (2006).

The result of Pentastomida found on crabeating frog (F. cancrivora) around Surabaya and Sidoarjo identification research presented descriptive.

\section{Results and Discussion}

Based on this research using 50 sample of commonly human consumed frogs (F.cancrivora) collected from fish pond, trench and rice fields around Surabaya and Sidoarjo during march until may 2018, showing 34 sample of frogs are positive (Table 1 ) infected by pentastomida.

The frogs that were use in this research is $C$ rab-eating frog ( $F$. cancrivora) because it is the most common frog consumed by human around Surabaya and Sidoarjo, beside the other two species that were mentioned was difficult to find. 
The identification of positive samples on commonly human consumed frog's peritoneum cavity and hindlimbs muscle using SemichenAcetic Carmine staining method refered to Kuhlmann (2006) and as identification key were used by Riley and Self (1980); Röhlig et al. (2010); and Christoffersen and De Assis (2013).

Table 1. Pentastomida infection on commonly human consumed frog (F.cancrivora) around Surabaya and Sidoarjo.

Pentastomida were found on body cavity,

\begin{tabular}{ccc}
\hline & $\begin{array}{c}\text { Positive } \\
\text { samples } \\
(+)\end{array}$ & $\begin{array}{c}\text { Negative } \\
\text { Samples } \\
(-)\end{array}$ \\
\hline $\begin{array}{c}\text { Samples } \\
50\end{array}$ & 34 & 16 \\
\hline
\end{tabular}

and hindlimbs muscle of frogs has
characteristics small and white coloured body, resembles nematode worm, annulated body from $1 / 3$ body until posterior of the body, the anterior part (head) larger than the medial part, and posterior part has sharp shaped. Each annulus carries a broad band of annular pits. Pentastomida's cuticle tend to uncolour or transparent, so internal organs of pentastomida are clearly visible. Pentastomida has two pairs of retractile hooks around its head for plugging in on peritoneum cavity and hidlimbs muscle of the frog. Pentastomida has pear-shaped mouth. The length of pentastomida that were found is about $12 \mathrm{~mm}$ until $20 \mathrm{~mm}$.

Macroscopic overview of Pentastomida which was found on peritoneum cavity and hindlimbs muscle of F.cancrivora under magnifier. Pentastomida was found on hindlimbs muscle of F.cancrivora (Fig. 1), Pentastomida was found on peritoneum cavity of F.cancrivora (Fig. 2) measurement process using ruler to record the length of pentastomida body (Fig. 3).

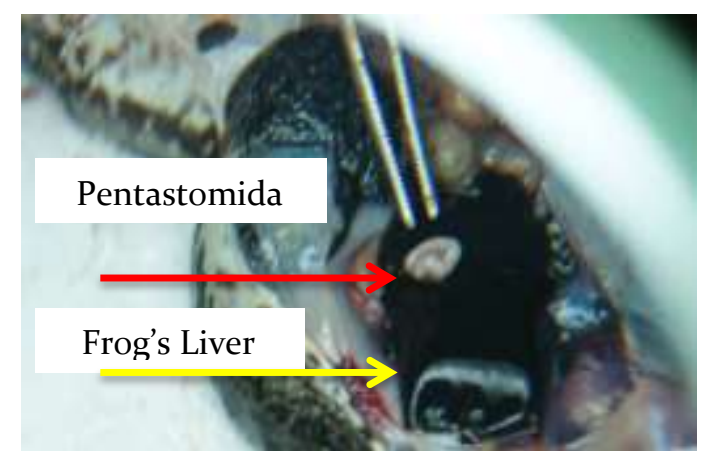

Figure 1. Pentastomida nymph found on hindlimbs muscle of F.cancrivora.

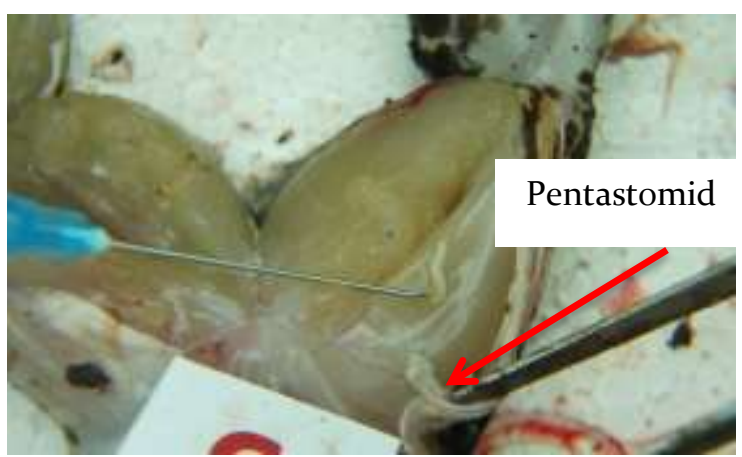

Figure 2. Pentastomida nymph found on body cavity of F.cancrivora.

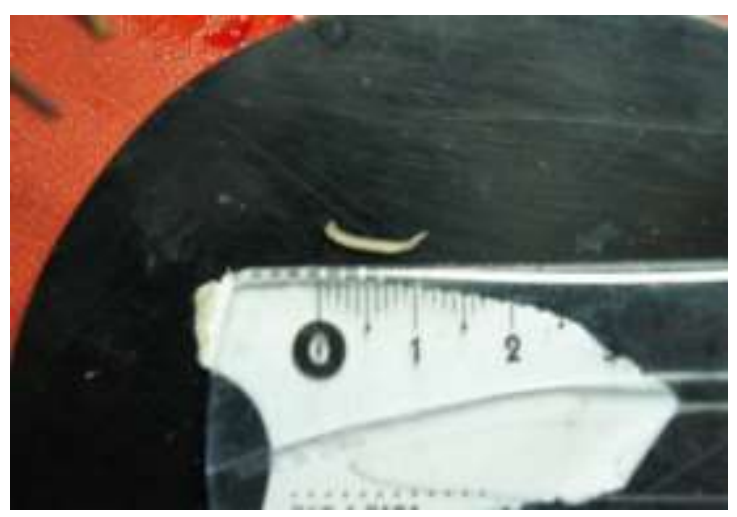

Figure 3. Measurement of pentastomida length using ruler.

Microscopic overview of pentastomida under microscope using 40x and 100x magnification. Anterior (head) part of pentastomida (Fig. 4), body part (dorsal) of pentastomida (Fig. 5), body part (ventral) of pentastomida (Fig. 6) and posterior part of pentastomida (Fig. 7).

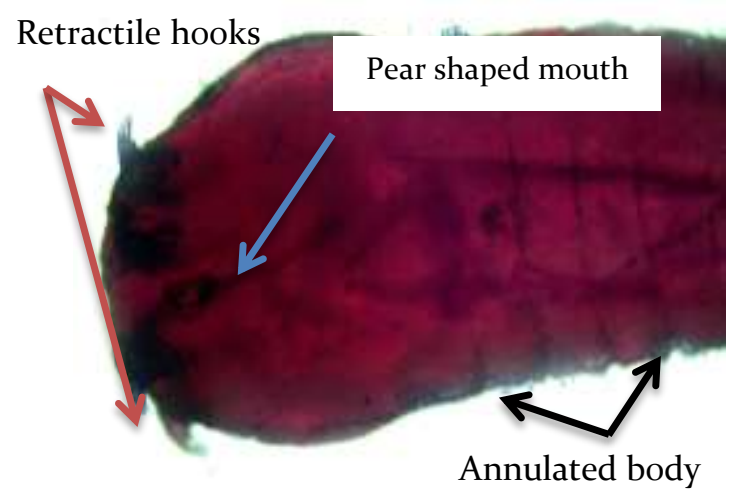

Figure 4. Anterior side of pentastomida nymph found on frog body (40x) using Semichen-Acetic Carmine staining. 


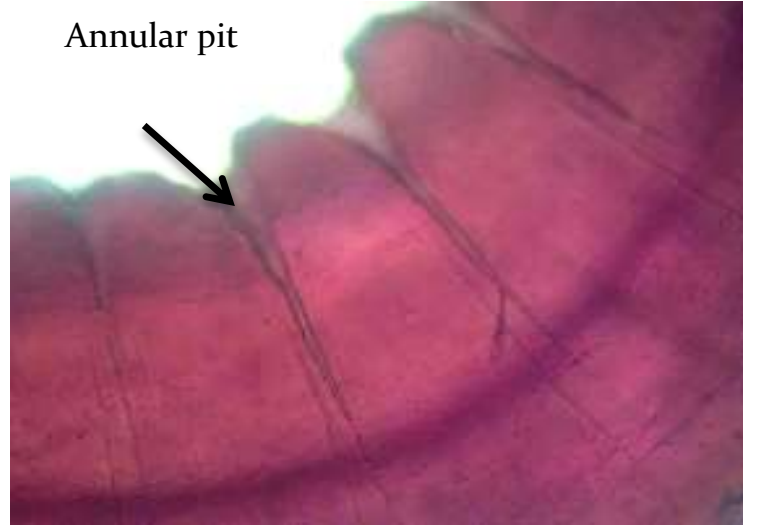

Figure 5. Annular pit of pentastomida nymph found on frog body (100x) using Semichen-Acetic Carmine staining.

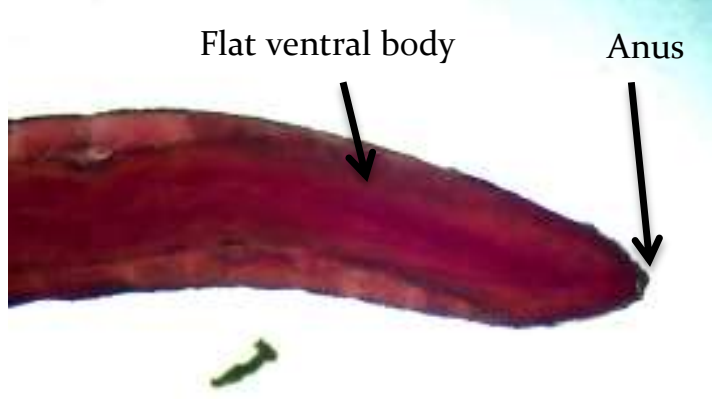

Figure 6. Posterior (ventral) side of pentastomida nymph found on frog body (40x) using Semichen-Acetic Carmine staining.

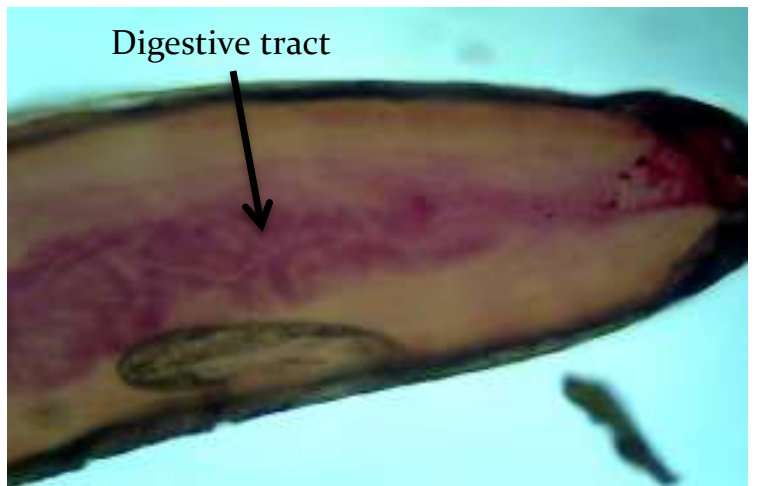

Figure 7. Digestive tract of pentastomida nymph found on frog body (100x) using Semichen-Acetic Carmine staining.

In the anterior side (head) of pentastomida that were found consists of mouth surrounded by retractile hooks. There can be seen two pairs of retractile hooks and a pear-shaped mouth. There also can be seen the annulating body of pentastomida. The figure showing the anteriodorsal side of pentastomida nymph. (Fig. 4).

The annulating body has pit called annular pit (Fig. 5). The sharp-shaped posterior side of pentastomida nymph showing the anus, and the flat ventral body of pentastomida (Figure 6). With 100x magnification of posterior side of pentastomida nymph can be seen digestive tract of pentastomida (Fig. 7).Based on Röhlig et al. (2010) record, the frog that were used in this research have been infected by pentastomida. The authors mentioned locality of the frog that infected by pentastomida is in East Java. In other words, the chance of human consumed frog infected by pentastomida around Surabaya and Sidoarjo is high. Then, pentastomida found in F.cancrivora are examined microscopically, in the anterior side (head) of pentastomida that were found consists of pear-shaped mouth surrounded by retractile hooks. There can be seen two pairs of retractile hooks and a pearshaped mouth. There also can be seen the dorsal body has annulus, while the ventral body is flat. Each annulus connection has annular pit. It has thick cuticle. The posterior side of pentastomida is sharp-shaped. After staining with SemichenAcetic Carmine technique, the posterior side of pentastomida showing the "sewer" tract. According to references from Riley and Self (1980) where the dispersion and macroscopic characteristics of pentastomida are found. It is in line with Christoffersen and De Assis (2013) especially the characteristics of the head of found parasite relate to pentastomida.

Based on pentastomida found characteristics and body length, only one stage can be found, nymphs. According to Riley and Self (1980) the adult of pentastomida are much larger than the nymphs. The adult are characterised a globular cephalothorax. Separated from the abdomen by a narrow neck formed of two annuli with the second annulus forming the narrowest region of the neck. The abdomen is twisted about its longitudinal axis and spirally coiled. Each annulus carries a broad band of annular pits (openings of the chloride cells) and these pits help to count the annuli. Especially in gravid females distended with eggs. From the characteristics above, the adult stage of pentastomida were not found. In the same literature mention the male are permanent juvenile. Considering the juvenile precocity of the male nymphs and the similarities between the nymphs and adult males in such aspects as the body dimensions, the distinct annular depressions, the absence of a distinct neck and the lack of spiraling of the body, the author proposes the hypothesis that the so-called adults are permanent juveniles which become 
sexually mature precociously in the intermediate host.

\section{Conclusions}

In this research using 50 samples there were 34 samples postive infected by pentastomida. The percentage reaching $68 \%$ which means the infection of pentastomida on frog is relatively high. Frog is one of intermediate host of pentastomida. Because pentastomida was not found on respiratory tract of the frog. Pentastomida that were found on frogs body is a nymph. Pentastomida confirmed infects human consumed frog from area of Surabaya and Sidoarjo.

\section{References}

Annable, T. J., and Metcalfe, D. C. 2012. Intraocular Sparganosis (Platyhelminthes: Cestoda: Pseudophyllidea: Diphyllobothriidae) in the Green Tree Snake Dendrelaphis punctulatus (Serpentes: Colubridae: Colubrinae) Herpetofauna, 42 (1/2): 51-55.

Barnes, Robert D. 1982. Invertebrate Zoology. Philadelphia, PA: Holt-Saunders International. pp. 880-881. ISBN o-03056747-5.

Cha, J. Y., Han, E. T., Shin, E. H., Park, J. H., Chu, J. P., Hirota, M. and Nawa, Y. 2003. An outbreak of gnathostomiasis among Korean emigrants in Myanmar. Am. J.Trop. Med. Hyg. 69(1): 67-73.

Cho, S. H., Kim, T. S., Kong, Y., Na, B. K., and Sohn, W. M. 2007. Larval Gnathostoma hispidum detected in the red banded oddtooth snake, Dinodon rufozonatum rufozonatum, from China. Korea. J. Par. 45(3):191-198.

Chomel BB, Belotto A, Meslin FXE. Wildlife, exotic pets, and emerging zoonoses. Infect Dis. 2007;13:6-11.

Christoffersen M.L., and De Assis J.E., 2013. A systematic monograph of the Recent Pentastomida, with a compilation of their hosts. Zoologische Mededelingen 87: 1-206.

Gałęcki R, Sokół R, Dudek A. 2016. Tongue worm (Pentastomida) infection in ball pythons (Python regius) - a case report. Ann Parasitol. 2016;62(4):363-365. doi: 10.17420/ap6204.76. PubMed PMID: 28170213 .
Kuhlmann W.F. 2006. Preservation, Staining and Mounting Parasite Speciment. Page 8

Kusrini, Mirza D. and Alford R.A. 2006. Indonesia's Exports of Frog's Legs. Traffic Bulletin.Vol 21 No.1.

Kusrini, Mirza D. 2005. Edible Frog Harvesting in Indonesia: Evaluating Its Impact and Ecological Context [Thesis]. James Cook University.

Kusrini, Mirza D. 2013. Panduan Bergambar Identifikasi Amfibi Jawa Barat. Fakultas Kehutanan IPB dan Direktorat Kons.

Paré, J. A. 2008. An Overview of Pentastomiasis in Reptiles and Other Vertebrates. Journal of Exotic Pet Medicine. 17, 285-294.

Riley J., 1986, The biology of pentastomids. Adv. Parasitol., 25: 45-128

Riley, J. and R.J. Henderson, 1999. Pentastomids and the tetrapod lung. Parasitology, Supplement 119: 89-105:s[:-

Riley J. and Self J.T., 1980. On the systematics and life-cycle of the pentastomid genus Kiricephalus Sambon, 1922 with descriptions of three new species. Systematic Parasitology. 1(2): 127-140.

Riley J. and Self J.T., 1981, A redescription of Waddycephalusteretiusculus (Baird, 1862) Sambon, 1922 and a revision of the taxonomy of the genus Waddycephalus (Sambon, 1922), pentastomid parasites of Asian, Australian and Indonesian snakes, sEEP itw descriptions of eight new species, Systematic Parasitology 3, 243-257.

Röhlig D., Dunlop J.A., Grau J.H. and Friederichs A., 2010. An annotated catalogue of the tongue worms (Pentastomida) held in the Museum für Naturkunde Berlin, Zoosyst. Evol. 86 (1) 2010, 129-154.

Sukara, E., I. SL. Tobing. 2008. Industri Berbasis Keanekaragaman Hayati, Masa Depan Indonesia. Vis Vitalis. 1: 1-12.

Sundar, S. B., Palanivelrajan, M., Kavitha, K. T., Azhahianambi, P., Jeyathilakan, N., Gomathinayagam, S., Latha, B. R. 2015. Occurrence Of The Pentastomid Porocephalus Crotali (Humboldt, 1811) In An Indian Rat Snake (Ptyas Mucosus): A Case Report. J. Par. Diss. 39(3): 401-404. 
Tappe, D., and Büttner D. W. (2009). Diagnosis of Human Visceral Pentastomiasis. PLoS Neglected Tropical Diseases. 3(2), e320.
Wright K.M. and Whitaker B.R. 2001. Amphibian Medicine and Captive Husbandry. Krieger Publishing Company, Malabar, FL. 